\title{
"Dilatation" of the left renal vein on computed tomography in children: a normal variant
}

\author{
J.M.Zerin, R.J.Hernandez, A. B.Sedman and R.C. Kelsch \\ University of Michigan Hospitals, Ann Arbor, Michigan, USA \\ Received: 24 October 1990; accepted: 5 November 1990
}

\begin{abstract}
Compression of the left renal vein (LRV) between the superior mesenteric artery and the aorta is thought to be a cause of hematuria, periureteral and gonadal varices, and varicocele ("Nutcracker phenomenon"). Previous investigators have suggested that this diagnosis can be made on computed tomography when the LRV ratio $\geq 1.5$ (the diameter of the LRV proximal to the aorto-mesenteric angle divided by the diameter of the LRV distal to the aorto-mesenteric angle). This study was designed to establish the normal range for the LRV ratio on CT in children. The LRV ratio was measured in thirtynine consecutive children undergoing intravenously enhanced CT of the abdomen. None of the children had hematuria on urinalysis immediately before or after the CT. Children with any known abnormality involving the kidneys, adrenal glands, IVC, or renal or gonadal veins were excluded. The patients ranged in age from 3.4 to 18.5 years (mean $=10.6$ years). LRV ratio ranged from 0.78 to 2.00 $($ mean $=1.46 ;$ S.D. $=0.312)$. Twenty of the 39 children $(51.3 \%)$ had a LRV ratio $\geq 1.50$. The conclusion is that the normal range for the LRV ration is too wide for it to be useful in diagnosing LRV entrapment and that a LRV ratio $\geq 1.5$ on $C T$ is normal in children.
\end{abstract}

Compression of the left renal vein (LRV) between the superior mesenteric artery and the abdominal aorta in the aorto-mesenteric angle has been implicated as a cause of occult left glomerular hematuria, periureteral and gonadal varices, and varicocele in children and adults [1-4]. Bleeding is thought to be secondary to left renal vein hypertension and has been reported with and without angiographically demonstrable varices [3,5-7].

However, there is controversy, both in regard to the frequency of the "nutcracker phenomenon" as a cause of hematuria in children, as well as the manner in which this condition can be reliably diagnosed. LRV to inferior vena cava (IVC) pressure relationships have been studied in adults [8]. However, normal values for LRV pressures have not been reported in children. In addition, angiographic findings can be misleading and retrograde flow within the left gonadal vein may be a normal finding in the absence of LRV or caval obstruction [9].

On computed tomography (CT) and sonography, the LRV between the renal hilum and the aorto-mesenteric angle (preaortic LRV) is frequently noted to be larger in diameter than the segment of the LRV between the aortomesenteric angle and the IVC (postaortic LRV). This "dilatation" of the preaortic segment of the LRV can be quantified by dividing the maximum diameter of the preaortic LRV by the maximum diameter of the postaortic LRV (LRV ratio). It has been suggested that a LRV ratio $\geq 1.5$ (i. e., the preaortic LRV is at least $50 \%$ wider than the postaortic LRV) represents dilatation secondary to compression of the LRV at the level of the aorto-mesenteric angle and may provide a non-invasive alternative to angiography in the diagnosis of the "nutcracker phenomenon" in patients with hematuria [5-6]. However, it has also been suggested that dilatation of the proximal LRV on either sonography [10] or computed tomography [11] may be a normal variant in both children and adults. The present investigation was undertaken to establish the normal range for the LRV ratio in children undergoing CT of the abdomen.

\section{Materials and methods}

Children undergoing intravenously enhanced computed tomography of the abdomen were prospectively included in the study. For inclusion the patients had to meet the following criteria: (1) Verbal informed consent was obtained. Children whose parents refused consent and those whose parents were unavailable (most of the inpatients) were excluded. (2) Each child provided a voided sample of urine for dip stick urinalysis immediately prior to or immediately following the CT examination. Children who could not provide a voided urine sample were excluded. None of the urine samples were obtained by "bag" or catheterization. Dipstick urinalysis was performed using urine test strips (Chemstrip-Boehringer Mannheim Diagnostics). Two children testing positive for hematuria were excluded. (3) Patients with any known renal or adrenal abnormality, prior retroperitoneal surgery, or thrombosis, varices, or other visible abnormality involving the IVC or the renal or gonadal veins were excluded. 
Table 1. Intra-observer consistency in measurement of the LRV segments and ratio

\begin{tabular}{|c|c|c|c|c|}
\hline & $\begin{array}{l}\text { Measurement } \\
1(\mathrm{~cm})\end{array}$ & $\begin{array}{l}\text { Measurement } \\
2(\mathrm{~cm})\end{array}$ & t-test ${ }^{a}$ & Correlation $^{b}$ \\
\hline $\begin{array}{l}\text { Pre-Aortic LRV } \\
\text { Mean. } \\
\text { Range }\end{array}$ & $\begin{array}{l}0.62 \\
0.26-0.91\end{array}$ & $\begin{array}{l}0.59 \\
0.23-1.07\end{array}$ & $p>0.05$ & $\mathbf{R}=0.807$ \\
\hline $\begin{array}{l}\text { Post-Aortic LRV } \\
\text { Mean } \\
\text { Range }\end{array}$ & $\begin{array}{l}0.43 \\
0.18-0.62\end{array}$ & $\begin{array}{l}0.42 \\
0.22-0.71\end{array}$ & $p>0.05$ & $\mathrm{R}=0.814$ \\
\hline $\begin{array}{l}\text { LRV Ratio } \\
\text { Mean } \\
\text { Range }\end{array}$ & $\begin{array}{l}1.47 \\
0.2-2.05\end{array}$ & $\begin{array}{l}1.45 \\
0.74-2.12\end{array}$ & $p>0.05$ & $\mathbf{R}=0.756$ \\
\hline
\end{tabular}

${ }^{a} \mathrm{P}>0.05$ on paired t-test suggests no significant difference between the means of the repeated measurements from the two samples.

All R values listed (Pearson Product-Moment correlation) suggest close correlation between paired measurements from the two samples and correspond to $p<0.0001$

Table 2. LRV measurements and ratios in 39 patients with negative urinalysis

\begin{tabular}{llll}
\hline & $\begin{array}{l}\text { Preaortic } \\
\text { LRV }(\mathrm{cm})\end{array}$ & $\begin{array}{l}\text { Postaortic } \\
\text { LRV }(\mathrm{cm})\end{array}$ & LRV ratio \\
\hline Mean & 0.61 & 0.42 & 1.46 \\
Range & $0.25-0.99$ & $0.20-0.63$ & $0.86-2.00$ \\
Standard deviation & 0.15 & 0.09 & 0.31 \\
\hline
\end{tabular}

CT examinations were performed on a GE-9800 scanner with a $512 \times 512$ matrix. Scan times were 2 seconds each with section thickness of $10 \mathrm{~mm}$ and scan intervals of $10 \mathrm{~mm}$. All patients were examined in the supine position and the studies were performed following the intravenous administration of standards dosages of either Hypaque meglumine $60 \%$ (diatrizoate meglumine) or Omnipaque-300 (lohexol). CT examinations were performed as indicated by the clinical history. No additional images were obtained specifically for the purpose of this study.

The diameters of the preaortic LRV and the postaortic LRV were measured with electronic calipers and the LRV ratio was computed in each case (Figs.1,2). Measurements were made of the largest diameters of the preaortic and postaortic segments perpendicular to the axis of the vessel. Care was taken to ensure that as much as possible the left renal artery was excluded from the measurement. The error in the measurements resulting from partial volume averaging theoretically should affect both the proximal and distal seg- ments of the LRV equally. Previous investigators have shown that measurements of the diameters of the preaortic and postaortic segments of the LRV and the LRV ratio on CT (using the same technique as above) correlate well with the same measurements on realtime sonography and in cadaver specimens [10].

The measurements were all done by the same observer (JMZ). Each measurement was done twice (on two separate days) with the observer blinded to the previous results. The paired measurements were averaged for each patient. Intra-observer variability between the two sets of measurements was assessed using a paired t-test and Pearson Product-Moment correlation.

The LRV measurements and ratio were also done on up to two other examinations in patients who had multiple examinations of the abdomen, to assess changes in the ratio within individual patients on different examinations. The LRV ratios obtained on the different examinations were compared using a paired t-test and Pearson Product-Moment correlation.

\section{Results}

Forty-two children were enrolled in the study. The renal vessels could not be satisfactorily seen on CT in three patients. Of the remaining 39 patients, there were 24 boys and 15 girls ranging in age from 3.4 years to 18.5 years $($ mean $=10.6$ years $)$.

Intra-observer consistency in performing the measurements of the LRV was very good (Table 1). The averaged renal vein measurements and ratios are summarized in Table 2. The diameter of the preaortic LRV ranged from $0.25 \mathrm{~cm}$ to $0.99 \mathrm{~cm}($ mean $=0.61 \mathrm{~cm} ;$ S. D. $=0.15 \mathrm{~cm})$ and the diameter of the postaortic LRV ranged from $0.20 \mathrm{~cm}$ to $0.63 \mathrm{~cm}($ mean $=0.42 \mathrm{~cm} ;$ S.D. $=0.09 \mathrm{~cm})$. The LRV ratio ranged from 0.78 to $2.00($ mean $=1.46 ; \mathrm{S} . \mathrm{D} .=0.31)$. The $95 \%$ confidence intervals for the mean LRV ratio is (1.36, 1.56). Twenty (51.3\%) of the 39 children had a LRV ratio $\geq 1.5$. In all cases the $L R V$ as it passed between the aorta and the SMA was narrower than either the preaortic or postaortic segments of the vein. None of the children had CT evidence of gonadal, ureteral, or other retroperitoneal varices (a criterion for inclusion in the study).

Twenty-six patients had multiple studies. Measurements of the LRV were made on one prior CT examination in each of 26 patients and on a second prior $\mathrm{CT}$
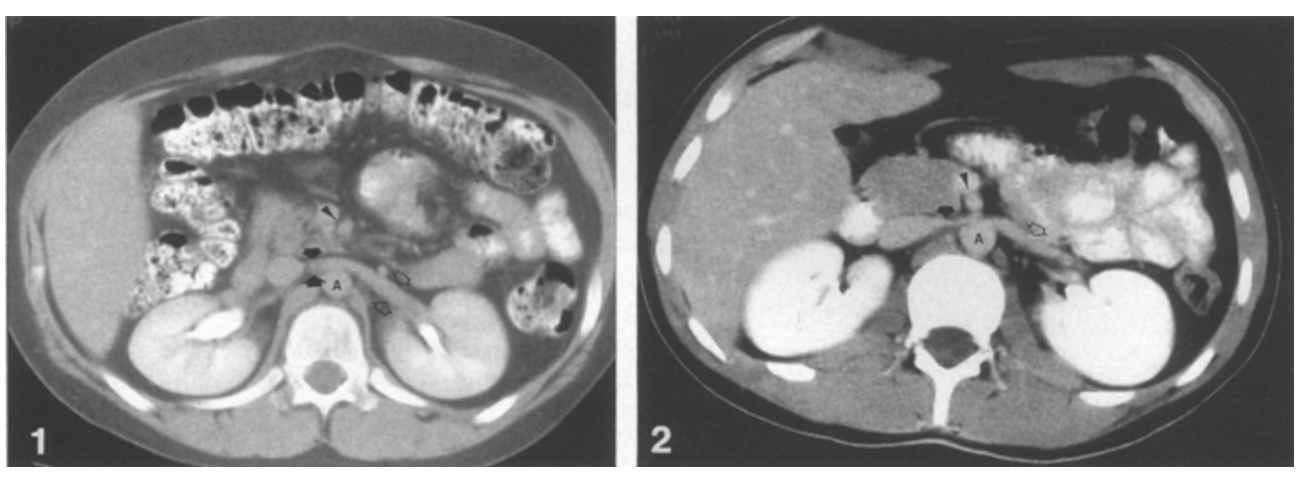

Fig. 1. Axial CT image through the left renal vein in a 12 year old boy with negative urinalysis. The pre-aortic LRV (open arrows) measures $0.78 \mathrm{~cm}$ and the post-aortic LRV (closed arrows) measures $0.43 \mathrm{~cm}$ producing an LRV ratio of 1.81. The SMA (arrowhead) and aorta (A) are quite far apart with a specious aorto-mesenteric angle. There was no abnormality visible on the study
Fig. 2. Axial CT image through the left renal vein in a 18.5 year old boy with negative urinalysis. The pre-aortic LRV (open arrow) measures $0.71 \mathrm{~cm}$ and the post-aortic LRV (closed arrow) measures $0.37 \mathrm{~cm}$ producing an LRV ratio of 1.92 . The LRV is severely narrowed in the aorto-mesenteric angle. SMA (arrowhead) and aorta (A). There was no abnormality visible on the study 
examination in 19 patients. Although the means for the LRV ratio for the three exam groups were closely correlated on t-tests, the LRV ratios for individual patients on different examinations did not correlate significantly (Pearson product-moment correlation test).

\section{Discussion}

The appearance of hematuria in an otherwise healthy child is a common clinical problem which frequently induces considerable anxiety both on the part of the family as well as the physician caring for the child. Most hematuria in children is non-glomerular in origin and is usually secondary to urinary tract infection. Trauma, calculus and neoplasm are less common causes [12]. The cause may never be discovered in a significant number of patients [13].

Bleeding of glomerular origin in children implies a renovascular etiology. Left renal vein hypertension secondary to entrapment of the LRV between the SMA and the aorta ("Nutcracker" phenomenon) is an uncommon cause of left-sided glomerular hematuria, gonadal and ureteral varices, and varicocele [1-4]. Compression of the retroaortic or circumaortic left renal vein between the aorta and the spine has been reported to be able to produce a similar result ("posterior Nutcracker") $[14,15]$.

Renal venography and measurement of pressure gradients within the renal veins and IVC would be the most direct method for demonstrating renal vein hypertension [5]. However, such invasive examinations are rarely indicated in children with hematuria of unknown source, and a noninvasive method of diagnosis would be desirable.

Renal vein compression in the aorto-mesenteric angle has been diagnosed in patients with gonadal and/or periureteral varices visible on cross-sectional imaging studies such as ultrasound and CT [4, 7]. However, precise criteria have not been established for the diagnosis of significant LRV compression on such non-invasive imaging studies when varices or varicocele cannot be demonstrated. While it has been previously suggested that the finding of a LRV ratio $\geq 1.5$ in a patient with glomerular hematuria is suggestive of renal vein compression, the present study shows that the normal range for the LRV ratio in children is too wide for it to be of any value in the diagnosis of this disorder. The normal range for the LRV ratio in children based on the present sample extends from 0.83 to 2.09 (accepting two standard deviations on either side of the mean) with $51 \%$ of the patients having a LRV ratio $\geq 1.5$. In addition, there is tremendous variability in the measurement of the LRV ratio on different examinations in individual patients, presumably related to unpredictable changes in renal blood flow, mesenteric flow, and degree of inspiration (Valsalva) during scanning.
Acknowledgement. K. Schwarz, R. T. for reloading a seemingly endless number of old examinations back onto the disc and Denise Wesley, R. N. for performing the urinalyses.

\section{References}

1. Beinart C, Sniderman KW, Saddekni L, Weiner M, Vaughan D, Sos TA (1982) Left renal vein hypertension: a cause of occult hematuria. Radiology 145: 647

2. Wolfish NM, McLaine PN, Martin D (1986) Renal vein entrapment syndrome: frequency and diagnosis. A lesson in conservatism. Clin Nephrol 26: 96

3. Takahashi Y, Akaishi K, Sano A, Kuroda Y (1988) Intra-arterial digital subtraction angiography for children with idiopathic renal bleeding: a diagnosis of nutcracker phenomenon. Clin Nephrol 30: 134

4. Trambert JJ, Rabin AM, Weiss KL, Tein AB (1990) Pericaliceal varices due to the nutcracker phenomenon. AJR 154:305

5. Sacks BA, Gomori J, Lerner M, Masters R, DeWolfe W (1981) Left renal venous hypertension in association with the nutcracker phenomenon. Cardiovasc Intervent Radiol 4: 253

6. Nishimura Y, Fushiki M, Yoshida M, Nakamura K, Imai M, Ono T, Morikawa S, Hatayama T, Komatz Y (1986) Left renal vein hypertension in patients with left renal bleeding of unknown origin. Radiology 160: 663

7. Weiner SN, Bernstein RG, Morehouse H, Golden RA (1983) Hematuria secondary to left peripelvic and gonadal vein varices. Urology 81

8. Beinart C, Sniderman KW, Tamura S, Vaughan ED Jr, Sos TA (1982) Left renal vein to inferior vena cava pressure relationship in humans. J Urol 127: 1070

9. Lerner MA, Sacks B, Shapiro G (1981) Retrograde flow in the left gonadal vein at abdominal angiography: an anatomo-physiological review and clinical assessment. Urol Radiol 3: 149

10. Shintaku N, Takahashi Y, Akaishi K, Sano A, Kuroda Y (1990) Entrapment of left renal vein in children with orthostatic proteinuria. Pediatr Nephrol 4: 324

11. Buschi AJ, Harrison RB, Brenbridge ANAG, Williamson BRJ, Gentry RR, Cole R (1980) Distended left renal vein: CT/sonographic normal variant. AJR 135: 339

12. Ingelfinger JR, Davis AE, Grupe WE (1977) Frequency and etiology of gross hematuria in a general pediatric setting. Pediatrics 59: 557

13. Vehaskari VM, Rapola J, Koskimies O, Savilahti E, Vilska J, Hallman N (1979) Microscopic hematuria in schoolchildren: epidemiology and clinicopathologic evaluation. J Pediatr 95: 676

14. Lau JLT, Lo R, Chan FL, Wong KK (1986) The posterior "Nutcracker": Hematuria secondary to retroaortic left renal vein. Urology 28: 437

15. Positano N, Nadalini VF, Bruttini GP (1980) Hematuria due to circumaortic left renal vein. Urology 16: 73

J. Michael Zerin, M. D.

Department of Radiology

Section of Pediatric Radiology

University of Michigan Hospitals

1500 East Medical Center Drive

Ann Arbor, Michigan 48109-0252

USA 